\title{
Theories of the development of human communication
}

\author{
Jonathan Delafield-Butt, UNIVERSITY OF COPENHAGEN/UNIVERSITY OF EDINBURGH \\ and Colwyn Trevarthen, UNIVERSITY OF EDINBURGH
}

\begin{abstract}
This article considers evidence for innate motives for sharing rituals and symbols from animal semiotics, developmental neurobiology, physiology of prospective motor control, affective neuroscience and infant communication. Mastery of speech and language depends on polyrhythmic movements in narrative activities of many forms. Infants display intentional activity with feeling and sensitivity for the contingent reactions of other persons. Talk shares many of its generative powers with music and the other 'imitative arts'. Its special adaptations concern the capacity to produce and learn an endless range of sounds to label discrete learned understandings, topics and projects of intended movement.
\end{abstract}

\section{Keywords}

Motives, emotions, creativity, infant development, intersubjectivity, cooperative awareness, narrative, ritual, meaning, musicality.

\section{Introduction - creating a human self: from intercellular cooperation to the shared imagination of culture}

\subsection{Making persistent individuals}

This paper discusses evidence in human development for anticipatory adaptations of body and brain that create learning of communication, particularly the learning of language. Inborn endowments for expressive movement enable human infants to share intentions, experiences and emotional evaluations, including aesthetic and moral feelings about 'self-with-other' experiences long before they speak. Expressive actions of young children motivate shared experience in conversation and eager cooperation in imaginative projects. These actions will mediate in the transmission of artificial practices, beliefs and techniques between individuals throughout life, and build knowledge and skills between generations.

We seek to give a more natural scientific foundation to abstract speculations in psychology and linguistics about how a child is led to master words and to understand what they mean - not only about what purposes and facts spoken words specify, but also how they 'feel' in live transmission. Prevailing theories of innate cognitive programs for discrimination and generation of the semantic and syntactical functions of text ignore the motivating and affective roots. They do not adequately reflect either the knowledge we have about vocal and postural communication in animals, or the development of unique vocal and gestural communication skills in human beings before they are able to speak. They disregard the capacity these expressive ways of moving have for cultivation into symbolic representations of projects, imaginative ideas and acquired knowledge (Merker, 2009a; Trevarthen, Delafield-Butt, and Schögler, 2011). They neglect the functional social space of meaning (Halliday and Matthiessen, 2004) and the poetic/emotional 'languages within 
language' (Fónagy, 2001), which guide the mastery of communication in early childhood (Bråten, 1998; Bråten, 2009). They regard emotional expression as a manifestation of stresses in regulation of the body and of information processing, not as integral with the causal motivators of adaptive action and experience (cf. Panksepp 1998, 2003; Panksepp and Trevarthen 2009; Trevarthen, 2009).

We examine how the organic or biological and psychological foundations of ideas carried in language emerge before birth in the body-with-brain and its feeling-full activities. We look for the antecedent developmental states and tendencies, from conception through gestation, to trace how the first movements and their intentions and affections become shared as imaginative narrative projects and enriched with consciousness of valued meaning (Bruner 1990; Trevarthen and Delafield-Butt, 2011). First, however, we are concerned with the nature of self-regulating systems in general, and how developing life forms, as agents, demonstrate general evolutionary principles of creativity and cooperation.

\subsection{Self-generated activity, context, and cooperative adaptation in natural phenomena}

Scientific description and measurement reveals that any enduring substance or system requires cooperation, both between its elements, and with its environment. Adaptive, self-organising connectedness and rhythmic harmonies of process and form give rise to a unique organisation in living organisms (Whitehead, 1929; Prigogine and Stengers, 1984). The self-sustaining dynamic relationships between its elements, their mutual active values, are also creative. They determine the development or 'ontogeny' of that kind of being - how it will interact with different conditions to sustain its individual being. Anticipatory adaptations cope with probable change in circumstances as Whitehead says, even inorganic 'organisms' "create their own environment" (Whitehead, 1925, pp. 138).

A living organism sustains its creative form of organisation by processes of growth and activity, challenging its relationship with the environment. From this we infer that the function of intelligence in the regulation of the vitality of an animal, including its communication of purposes, feelings and understandings to other individuals in a shared world for cooperative goals, is to create and propagate its ways of moving to use its accessible world in self-sustaining ways. Regulation of vitality and agency of the body is the adaptive function of the animal's nervous system, in all its parts, and as a whole sensory-motor Self (Sherrington, 1906; Merker, 2005; Packard, 2006; Northoff and Panksepp, 2008).

\subsection{Ontogenesis of intelligent life forms and their societies}

Living organisms grow and survive in epigenetically regulated relations with their surroundings, changing expression of their genes in creative response to circumstances, reproducing bodies and life histories that both 'expect' and 'depend on' environmental opportunities for their vitality (Bateson 1894; Whitehead, 1929; Bateson, 1980). The molecular ecology of genes in living cells can only thrive if the epigenetic systems and the organs of the life form they are within function and develop as they are adapted to do. The dynamic neural regulations in an animal organism have inner and outer aspects of 'self-related processing' (Northoff and Panksepp, 2008), and a child thrives only if it inspires the human world with a love generated by a powerful desire to meet the child's needs for survival and development (Narvaez, Panksepp, Schore, and Gleason, 2011). There is an inborn collaboration between a supportive ecology inside each animal, the 'milieu interne' of Claude Bernard (1865), and an arousal of instincts for behavioural engagements with media and agents outside the body. These together, the self-maintenance of vital states and the action in the world, provide the essential adaptive structure for psychobiological development and the success of 
animals and humans and of their societies. Human societies depend on the impulses of young children to find parental companions, and to inspire affection and playful desires for sharing experiences and making them meaningful. The natural motives in child and parent are complementary 'co-adaptations' for the life of human society (Narvaez, Panksepp, Schore, and Gleason 2011).

In the development of this human child the principle of creative and cooperative vitality is repeated over all the scales of organisation of the units of vitality, from beginnings in the fertilized egg, through the tissues and organs of embryo, fetus and developing child, to participation in the social organization of a culture, drawing on accumulated knowledge and skills (Trevarthen, Aitken, Nagy, Delafield-Butt, and Vandekerckhove, 2006).

\subsection{Consciousness is the prospective control of agency, generated for coordination and regulation of movement}

Animals as embodied and motivated agents are coherent and self-regulated. Their bodies are prepared to move with prospective control in an awareness of space and time that is created for integrated guidance of their limbs and senses (von Hofsten, 1993; von Hofsten, 2004; Lee, 2005). They act intelligently, with affective evaluation of what they are doing in the immediate present, what they may do in the more distant future, and what they remember having done in the past. This 'life world' in action (von Uexküll, 1957) can be elaborated by learning, but it cannot be created by learning - it learns in order to grow. Humans exhibit exceptionally rich 'autonoesis' or the making of a 'personal life history' (Tulving, 2002), as well as cultural 'socionoesis' or the making of a 'habitus' of meaning by 'story-telling' (Bruner, 1990; Bruner, 2003; Trevarthen, 2011a).

The brain is formed to be the generator of an intentional and feeling-full consciousness in an individual. Its spontaneous activity 'knows' ahead in time what any of its movement will do or lead to, 'expects' the effects of stimuli in a 'body-centred world', and can 'project' or 'associate' its experience of vital physiological arousal and need onto items of experience to give situations and objects affecting qualities or feelings (Sherrington, 1906; Lashley, 1951; Sperry, 1952; von Holst and von St. Paul, 1960; Gibson, 1966; Bernstein, 1967; Damasio, 2010). The evidence from embryogenesis confirms that the integrative neural mechanism is mapped early in development to excite prospective movement in integrated command of the form and functions of the body, with its environment-directed effectors and receptors and internal felt needs. In this behaviour field, different innate adaptive modes of activity and awareness (Trevarthen, 1986a), different 'arousals' of awareness with feeling (Pfaff, 2006; Stern, 2010), guide complementary functions between perceptions - of of objects and agents in the environment, of body movement, and of internal vital physiological need - to give 'self-related processing' ( Sherrington 1906; Northoff and Panksepp, 2008; Panksepp and Northoff, 2009).

The actions of the animal sustain physiological wellbeing by guiding locomotion through the media of the surrounding world with selective attention to local objects identified for their lifegiving potencies as good (i.e., to be sought for and taken up), bad (i.e., dangerous, to be avoided) or neutral (i.e., safe to ignore). These embodied principles of evaluation can be transmitted as signals to other individuals if they are endowed with the same sensory capacities enabling a sympathetic 'mirroring' of rhythmic patterns of body movement and inner regulatory dynamics (von Uexküll, 1957; Trevarthen, 1986b; Bråten, 2009).

A child's movements powerfully communicate to other human beings the inborn regulatory process of the human mind and their acquired modifications (Aitken and Trevarthen, 1997; Bråten and Trevarthen, 2007; Panksepp and Trevarthen, 2009). They display the 'motor images' which assist the planning of their efficient mastery of the mechanics of a heavy moving body with complex limbs (Bernstein, 1967), the spontaneous 'serial ordering' of their movements in body- 
related space and time (Lashley, 1951) and the 'prospective control' of the reach and force of their individual actions in this space-time field (Lee, 2005; Lee, 2009). When we move with grace and purpose we assimilate sensory input to guide output of our nervous system by a process that aims to control the future experience of our behaviour. This process becomes communicative by transfer of action-related information between intra- and inter-subjective realms (Trevarthen, 1986b; Gallese, 2001; Sinigaglia and Rizzolatti, 2011; Trevarthen et al., 2011). Learned complexes of gesture become habits of individual action and of cooperation in shared, cultural experience, including the imitative arts of music, theatre and dance, which, with poetry and song, bring the referential communication of language back to its interpersonal and self-sensing foundations (Fónagy, 2001; Malloch and Trevarthen, 2009).

\subsection{Communication in the making of animal society, human culture, and language}

The principles of animal semiosis, or social signalling, elucidated by Jacob von Uexküll (von Uexküll, 1926) were developed by Sebeok $(1977$; 1994) as a science of 'semiotics'. They affirm an evolutionary theory of human symbolic communication and the social foundations of language (Halliday, 1978; Rommetveit, 1998), and they elucidate how the special human aptitudes for invention of art and technology grow from the creative and cooperative abilities of expression and response which infants show (Stern, Hofer, Haft, and Dore, 1985; Trevarthen and Longotheti, 1987; Trevarthen, 1990; Reddy, 2008; Stern, 2010). Human beings transform their environment by projects and structures they invent: "The tool kit of any culture can be described as a set of prosthetic devices by which human beings can exceed or even redefine the 'natural limits' of human functioning" (Bruner, 1990). Infants and children are ready for this cultural creativity (Trevarthen, 2011a). They share an imaginative and highly emotional life in intimate and playful attachments with parents, peers and neighbours. Language amplifies and extends the intrinsic impulses and feelings for co-operative functioning, and becomes an historically elaborated descriptive and informative 'tool' for making shared projects more effective by describing flexible inventive forms of social coordination, perspective-taking and joint action (Tylén, Weed, Wallentin, Roepstorff, and Frith, 2010).

Cooperative rituals of art and technique support group mastery of the environment by expanding shared imagination as a history (Turner, 1982; Turner and Bruner, 1986; Donald, 2001). The building of cultural knowledge is aided by carrying messages through many generations in symbolic activities, products and language, transforming intelligence about the uses and qualities of the world and how individuals perceive one another and share purposes and feelings (Darwin, 1872; Vygotsky, 1978; Bruner, 1990; Bråten, 1998; Bråten, 2009). Speech and language depend on new motor skills and a special human enthusiasm for elaborate ritual and vocal learning (Merker, 2008; Merker, 2009a; Merker, in press; MacNeilage 2008; MacNeilage 2011), and on emotional communication in the 'musicality' of gesture and vocalization (Bloom, 2002; Lüdtke, 2011). In art, technology and language, these adaptations expand the capacity for communication of experiences and inventions through different 'loci of concern', from the immediate present realm of space and time, to future events, to remembered pasts, and to imagined, mythical or theoretical times and places (Donaldson, 1992).

\section{Cooperative vitality in the creation and nurture of a human communicative self before birth}

2.1 The first sixty days: cells cooperate to build tissues and organs of an embryo human being 
A human life begins with the creative act of two individuals coming together in intimacy, disengaged from practical concerns, with eagerness for life and joy in the risk of shared bodies, in impulsive activity that sends the sperms of the male toward the ova inside the female. Their hormonal mechanisms and physiological arousal systems are powerfully engaged (Pfaff, 2006). The fertilized human egg joins with a mother's body that is adapted to protect and aid the formations of the body and brain of a new form of primate. The creation of a new human life shows cooperation at all the levels of biological organisation (Trevarthen et al., 2006).

Cells produced by division of the fertilized egg regulate their gene activity by reciprocal, cooperative systems that govern how their populations will divide, migrate, and differentiate (Waddington, 1940). 'Sense data' appropriated between neighbouring cells through diffusible biomolecules, surface-surface contact, and mechanical tensions activate patterns of genes, which determine how cells will aggregate to form tissues and organs with different functions (Edelman, 1988). The polarised body is formed with sensitive head end and active posterior, and nervous and humoral regulations of a variety of arousals for world-related action and preservation of internal vitality, and their timing (Trevarthen et al., 2006). The central nervous system is integrated as the coordinator of a being that, though still immobile and insensitive, is formed for the joys and fears of a future mobile life in intelligent engagement with the environment (Beddington and Robertson, 1999).

Collaboration between the germ layers of the embryo begins early in embryogenesis, as each tissue "needs the help of its sister travellers..." (Pander, 1817). The endoderm forms the digestive tract that appropriates and digests food; the mesoderm becomes the visceral organs, muscles, and bone that make up the bulk of the body with its transformative and life-sustaining functions; and the ectoderm forms both the skin and all of the nervous tissue of the sense organs, brain, and peripheral nervous system with its sensory and motor components, somatic and visceral (Hamilton, Boyd, and Mossman, 1962). Both brain and skin are adapted for selective engagement with the outside world and for protecting and regulating the energy balance of vitality inside.

\section{The Fetus Develops Organs for Life in an Imaginative Cultural World}

\subsection{Growth of centrencephalic systems for intentions, emotions and conscious agency}

According to the 'centrencephalic' theory of consciousness, first presented by Penfield and Jasper (1954), the midbrain, though anatomically sub-cortical, is functionally supra-cortical. The subcortical upper brain stem and midbrain territories between the hypothalamus and superior colliculi are responsible for emotionally charged states of consciousness of our core embodied 'anoetic' conscious agency (Vandekerckhove and Panksepp, 2011), which serve basic generation of action, orientations to experience and emotional appraisals. These primary mental functions ontogenetically and functionally precede cortically-mediated cognitive ones. Cognition may enhance and assist with additional 'tools' for use by this core control system and its expansion in learning adaptation to external realities, but the primary motives and evaluations remain subcortically-mediated. Expression of this core consciousness makes intersubjective engagements of action and awareness possible (Watt, 2004).

The centrencephalic theory is confirmed by studies of the growth of intelligent activity and 'self-related processing' in the human embryo. The first integrative pathways of the brain are in the core of the brain stem and midbrain (Windle, 1970), and the earliest whole body movements, though undifferentiated in their goals, are coherent and rhythmic in time (Lecanuet, Fifer, Krasnegor, and Smotherman, 1995). When sensory input develops, there is evidence, not just of reflex response to stimuli, but of the intrinsic generation of prospective control of more individuated actions, before the neocortex is functional. In the third trimester of gestation, when the 
cerebral neocortex is beginning formation of functional networks, movements show guidance by touch, by taste and by responses to the sounds of the mother's voice, with learning.

After birth the infant's conscious activity soon exhibits what Sherrington (1906) called 'projicience' of sight and hearing to anticipate the location and properties of objects external to the body, and evaluation or 'affective appraisal' of those properties in relation to vital processes. The former are dependent on neocortex, but the latter are created in subcortical systems. A newborn infant has well-developed coordination of the body, expression of vital needs, and means for selective communication with the affectionate attentions of the mother and by engaging with her complementary adaptations for affectionate response to the infant's needs (Als, 1995). The role of the cerebral cortex, in imaginative identification and memorizing of features of the environment and of objects, and for refined sensory control of complex movements of manipulation and articulation of vocalizations, is critical for adaptation of practical activities and for communication by language learned in the years after birth. But the prenatal development of subjective and intersubjective motives demonstrates that the 'intentional core' and 'seat of consciousness', with emotional regulation of purposeful action and its communication, should not be identified with a learned 'executive' function of the cerebral cortices, as cognitive science proposes. Specifications for a body-centred neural field for perceptual guidance of whole-body action forms a scaffold for higher mental processes and more complex patterns of action, which are laid down in the fetal period by growth of additional structures of body and brain for sensory regulation of movements in an unstimulating, highly-controlled intrauterine environment (Trevarthen, 1985). The first motor, sensory, and interneuronal connections in humans at 35 to 40 days form a basic nerve network in advance of any receptor excitation.

\subsection{Fetal syntax: signs of self-generated feelings and imaginative intentions in the first and second trimesters of gestation}

After two months gestation the developing child already has body parts adapted for forms of action, awareness and communication characteristic of the human species (Hamilton et al., 1962; Trevarthen, 1985). Organs of selective awareness and communicative expression - mobile head, eyes, face, and vocal system - are differentiated and approximate to their adult forms. The first spontaneous body movements occur at this time (de Vries, Visser, and Prechtl, 1982; Prechtl, 1986). Cycles and rhythmical or pulsating bursts of movement of the early fetus indicate autogenous, i.e. 'self-generated', pacemaker systems that will animate perception of time and give tempo to later acts of communication (Wolff, 1966; Osborne, 2009; Trevarthen, 2009).

After three months, information from eyes, ears, nose, and mouth is carried in an impulse code and mapped out in central nerve circuits specified to relate movements in one body-related behavior field (Trevarthen, 1985). The precocious appearance of adaptively organized reaching and touching movements with postural control and accompanied by compensatory eye movements, indicates that the first organized efferent-afferent neural feedback loops, carrying signals from the brain to excite the peripheral motor effect and reflecting back sensations, are those representing a whole-Self-sensing system that controls the coordinated displacement of many body parts. Organized whole-body or body-part movements of the early fetus include 'bicycling' of the legs, turning the body in the womb, reaching to touch the placental and umbilical cord, and reaching to parts of the fetus's own body or a twin fetus (de Vries et al., 1982; Piontelli, 1992; Piontelli, 2010). All confirm that the fetal motor actions are enacted with prospective, Self-sensing control.

It is particularly important in relation to conversational skills that fetal arm movements may be aimed so the hands can feel the face and head (Piontelli, 2010). Studies of fetal behaviour using real-time ultrasonography demonstrate exploratory sensation-testing movements from as early as ten weeks, when innervated areas - lips, cheeks, ears, and parietal bone - are frequently touched by 
the hands, the fingers of which are themselves richly innervated with sensory fibres. These touches create autostimulatory feed-back; the action creates contact between the fingers and head, giving simultaneously a proprioceptive response, sensation of touch in the fingers, and sensation of touch in the innervated region. This action-generated loop may be considered as the precursor of intersubjective 'self-other' regulatory processes from which communication of mental states develops. Fetuses explore the boundary of the innervated and uninnervated regions at the anterior fontanel of the forehead, testing the differences in feed-back either side of the boundary (Piontelli, 2010, pp. 61-67).

Later in fetal development, other explorations of self and environment can be observed as the hands touch the eyes, the mouth, the uterine wall, and so on. And individual 'habits' appear, such as a propensity to fondle the umbilical cord, scratch at the placenta, or to make twin-directed movements (Piontelli, 1992; Piontelli, 2002; Jakobovits, 2009). Self-touching actions continue throughout life as restless gestural "self adaptors" (Ekman and Friesen, 1969), also very evident in animated face-to-face conversation (Kendon, 1980). They express a dynamic sense of self that communicates changing states of mind.

At two months of gestation the cortex has no neural cells and thalamo-cortical projections are just starting to grow (Larroche, 1981; Hevner, 2000), but there is sufficient sensory and motor nervous connectivity for dynamic proprioceptive motor control (Okado, 1980). At 31/2 months, quantified kinematic analyses indicate that fine movements of hands and fingers guided by sensitive touch, show a sequential patterning with modulation of arousal state that may give a grounding for 'narrative imagination', and ultrasound recordings of twin fetuses at $4 \frac{1}{2}$ months show regulations that distinguish movements of self-exploration from those directed to a twin, and this is taken to confirm a primary 'social awareness' (Castiello et al., 2010). Certainly, by 51/2 months the kinematic form of the arm movements of single fetuses confirms that 'imaginative' and 'self-aware' motor planning is operative (Zoia et al., 2007). This natural history of human movement appears to confirm the suggestion by Lashley $(1951$, p. 122) that propositional thought may depend on the spontaneous syntactic ordering of movements.

Movements are not only directed to engage with the external inanimate world or the body of the Self. Facial expressions in fetuses and movements of distress and curious exploration give evidence of emotions of discomfort or pleasure that may be adapted for communicating feelings. In the third trimester, separate movements of the facial muscles visualized by 4D ultrasound develop into complexes that define a 'cry face gestalt' or a 'laughter gestalt', expressing emotions that will communicate powerfully after birth in the regulation of parental care (Reissland, Francis, Mason, and Lincoln, 2011). Maternal hunger with depletion of energy supply to the fetus drives 'anxious' patterns of fetal movement. There is consensus in modern paediatrics that by twenty-four weeks the fetus should be considered a conscious agent deserving the same standard of medical care as adults (Royal College of Obstetricians and Gynaecologists, 2010). The mid-term human fetus has the foundations for the space-time defining functions of intention in action, and for the emotional regulation of aesthetic relations with the objective world and moral relations with other persons.

When considering the emergence of consciousness, it is important to note, however, that the special sense organs, having attained their basic function-specific form in the late embryo, are cut off from stimulation by morphological changes in the early fetal period (Hamilton et al., 1962; Trevarthen, 1985). While a self-regulating mobility is clearly functioning, the organs that will explore the rich variety of experiences after birth have no function. The eyelids grow over the cornea to fuse at $71 / 2$ weeks. They reopen at 6 months. The ear ossicles develop within a spongy mesoderm that remains to block transmission until the last fetal months, when a cavity forms around the ossicles. The tympanic cavity remains obliterated by endodermal thickening and swelling and is excavated shortly after birth in association with changes that accompany the onset of pulmonary respiration. Auditory discrimination appears possible only in the last trimester. From the second to sixth gestational months the nostrils are closed by epithelial plugs. 
At 6 months, the fetus awakens to a sensible world and the neurological and metabolic processes are sufficiently advanced for survival in an incubator, or with vital support from ventroventral contact with a parent's body in 'kangarooing'. The change to this level of competence is a sudden one, the 6-month-old fetus having achieved a characteristic state of sensori-motor readiness, including the fundamental controls for seeing. During the eighth and ninth lunar months, the infant develops muscle tone from lower to upper limbs and assumes a comfortable rest posture, but mobility is less than at early stages of prematurity. This is when the developing child takes the first steps to cooperate purposefully with another human being in regulation of arousal and appraisal of experiences.

Neuroblast production to establish the neocortex is maximum at 20 weeks, mid-gestation (Trevarthen, 2004). Sensory, motor and motivational representations in the cortex, and that will carry cognitive advancements, are mapped out, and its cells impregnated with affinities for connection with their complementary subcortical systems. It is important that the first developing regions - in the parietal, temporal and frontal cortices -- are the same ones that will undergo massive elaboration throughout life. Just these are uniquely enlarged in Homo sapiens sapiens, compared to earlier evolved Homo (Bruner, 2010). They are the tissues for cultural learning, and they include areas for language learning.

\subsection{Fetal sensitivity: rapid brain and muscle development for cultural learning and preparation for engagement in the third trimester of gestation}

Between 24 and 40 weeks gestation the human head grows more than the body as the delicately layered neocortical sheet expands. The positions and interconnections of its neurons depend not only upon input from the sensory relay nuclei of the thalamus, but especially from the motivation systems of the core Self already developed (Northoff and Panksepp, 2008). Cortical dendrites proliferate with the support of abundant interneuronal glia cells. These multiply at an accelerating rate toward a climax two weeks after term, accompanying the proliferation of dendrites and the development of synaptic fields (Trevarthen, 2004).

The cortex develops its characteristic folds in the final 10 weeks before birth and the patterning of gyri shows differences between the hemispheres characteristic of humans, which reflect asymmetries in sub-cortical self-regulating systems, the right side of the brain being more self-related or proprioceptive and the left being more discriminatory of environmental affordances and eventually directed to learn adaptive articulations of the hands and of vocal activity (Trevarthen, 1996). Importantly, areas later to be essential for perceiving and producing sounds of words are evident in the left hemisphere at 30 weeks. Complementary enlargements in the right hemisphere are adapted for both visual and auditory evaluations of other persons' expressions and identity.

The late fetus is in a quiescent state, but can be awakened and can learn. At seven months it shows cardiac accelerations and startles to sounds. While general body movements decrease, respiratory movements increase, as do face, tongue movements, smiling, eye movements and hand gestures. All these are forms of action that will serve not only in self-regulation, but in expression of self-related states for intimate communication and for learning language. Fetuses interact with the mother's movements and uterine contractures and, after 25 weeks, can learn her voice, a process that engages the right cerebral hemisphere (DeCasper and Prescott, 2009). There are also motor reactions to rhythmic sounds, such as the bass pulse of dance music, and melodies that the mother attends to frequently or performs on a musical instrument can be learned.

The last trimester is critical for elaboration of asymmetries of cerebral function adapted for cultural learning. First it will be necessary to form an intimate attachment with a caregiver, normally the mother, whose hormonal changes support special affectionate ways of acting that 
match the newborn's needs. The right hemisphere orbito-frontal system motivates affective communication with the musical prosody of infant-directed parental speech (Schore, 2011), and the left orbito-frontal cortex has a complementary adaptation for generation of affective signals by the infant (Trevarthen, 1996).

Beneath the cerebral cortex the brain generates fundamental rhythms for self-synchrony of movements of body parts and inter-synchrony in exchanges of signals of motives and emotions from other humans (Buzsáki, 2006), including the faster components that become essential for the learning of manipulative skills and the rapidly articulated movements of language or gestural signing (Condon and Sander, 1974; Trevarthen et al., 2011). Brain rhythms enable the fetus to move in coordination with the sounds of music and to learn certain melodies or musical narrations (Malloch, 1999; Gratier and Trevarthen, 2008). They also favour a selective sensitivity to expressive features that identify the mother's voice, which is mediated by the right hemisphere (Panksepp and Trevarthen, 2009; Turner and Ioannides, 2009). Respiratory movements and amniotic breathing appear several weeks before birth, and heart rate changes have been coordinated with phases of motor activity from 24 weeks (James, Pillai, and Smoleniec, 1995). This is indicative of the formation of a prospective control of autonomic state coupled to readiness for muscular activity on the environment, a feature of brain function, which Jeannerod (Jeannerod, 1994) has cited as evidence for the formation of cerebral 'motor images' underlying conscious awareness and purposeful movement.

\subsection{Proof of human impulses for self-expression and communication from the development of premature infants.}

Infants born four months before term can develop well if given ventro-ventral, skin-to skin contact in 'kangarooing', which compensates for the loss of the intimate amphoteronomic support provided within the mother's body (Als, 1995). Comparisons with traditional artificial intensive care confirm that kangaroo care benefits both infant and mother for intimacy of interaction and maternal feeding, reduces maternal distress, and leads to better development of communication through infancy (Tallandini and Scalembra, 2006). A recording made of a prematurely born infant in intimate body contact of 'kangarooing' with the father's body demonstrates that vocal expression and exchange by simple 'coo' sounds is possible at 32 weeks, and the timing of the alternating sounds of infant and father matches that of normal syllables and phrases in fully articulate speech (Trevarthen, 1999).

From the eighth month and through the first six weeks after full term birth, the neonate's mind is in a quiescent state, well-coordinated but mostly in a deep sleep, able to cooperate with support, comforting and breast feeding, but with limited curiosity for the new much richer environment.

\section{The infant's initiative toward cultural learning and language}

\subsection{Infant intentional communication as groundwork for the interpersonal and practical functions of language}

Immediately after birth, a healthy full-term infant may be attractively active, alert and responsive orienting to the mother's voice, showing interest and affection with well-directed movements of the whole body, of the eyes and face and of the gesturing hands. The baby may imitate expressions of head and eyes, face and mouth, voice or hands, and become involved in a dialogue with an attentive and affectionate parent, actively seeking a gently regulated imitative exchange with a responsive partner (Nagy and Molnar, 2004; Nagy, 2011). Accurate observations prove that the infant has 
innate prospective awareness and curiosity as a coherent self, and special intuitions for sharing activities and experiences. Human beings are born with both 'subjectivity' and 'intersubjectivity' (Trevarthen, 1979; Trevarthen, 1998; Nagy, 2008). Demonstration of the capacity for active interest and communication has transformed neonatal care (Brazelton, 1979). The increased activity in response to approach by a parent who offers eye-contact, gentle touching and the modulated vocalizations of motherese, the seeking of communication and imitative responses between them, confirm that the human brain is innately convivial and adapted for learning language (Papoušek, 1994). Cyclic sequences of movement become orchestrated to make 'narratives' that express internal regulations of vitality with an innate time sense (Wittmann, 2009).

Within a few weeks the 'protoconversational' behaviour is more quickly regulated by improvements in visual and auditory awareness and, in interaction with the adult behaviours this development attracts, the infant can take a precisely regulated part in a rhythmic exchange of visible and audible signals of vitality and relational emotions. The capacity for this sustained communication has been called 'primary intersubjectivity' (Trevarthen, 1979). By three months an intimate attachment with the mother is consolidated by increased playfulness with body movements and sounds, and games with the infant become attractive to the father and other family members as well. The play takes increasingly ritual forms in body games and song that attract interest and attuned response from the infant. A 'proto-habitus' of performances develops through the first semester, and the infant starts to adapt to the particular cultural forms of body expression and voice, learning to reproduce 'performances' for appreciation by others (Gratier, 2003; Gratier and Trevarthen, 2008). The baby becomes increasingly demonstrative, seductive and self-conscious as 'self-other' awareness grows (Reddy, 2008). This is a development of an 'anoetic' emotional consciousness of self and of other persons that requires no rational or articulate 'theory of mind', the later development of which is artificial and optional (Panksepp and Northoff, 2009).

By seven months more vigorous and more rapid rhythmic movements begin - banging with the hands, but also syllabic babbling, which appears to be the innate repetitive motor function that made learning of speech possible, as Darwin proposed (Darwin, 1871; MacNeilage, 2008; MacNeilage, 2011). The infant is also demonstrating a more intense awareness of the quality of response from a partner who seeks intimate communication, showing wary attention or distress and withdrawal if approached too directly by a stranger who 'does not know the game' (Trevarthen, 2005; Reddy, 2008). This manifestation of heightened temperament in sociability appears just before a striking change at 9 months in the infant's willingness to share a task that requires shared actions on objects in cooperative work (Trevarthen and Hubley, 1978; Hubley and Trevarthen, 1979). In preceding weeks, eagerness to look for, grasp and manipulate has been incorporated in person-person-object games with 'toys'. The infant's capacities to express shifting interests with movements of head, eyes and hands being recruited in intersubjectively created rituals of narration (Merker, 2009b). This joint performance has clear foundations in the spontaneous indicative and narrating movements of pointing with eyes and hands evident from birth (Trevarthen et al., 2011).

Throughout early development, a matching hierarchical set of rhythms of movement facilitates coordination of motives and actions between infant and adult. Perturbation tests prove that the infant is sensitive to both the affective quality of a parent's expressions and to their contingent timing (Murray and Trevarthen, 1985). The spontaneous movements of the infant demonstrate self-synchrony between body parts, and in communication infant and parent show precise inter-synchrony (Condon and Sander, 1974). Musical acoustic analysis of vocal exchanges in proto-conversations and singing play has demonstrated that the rhythmic and melodic patterns of music originate in an innate 'communicative musicality' that makes possible the close cooperation of human companionship (Merker, 2008). Difficulties due to abnormal development of motive processes in the infant, or to emotional disorder in the mother, are marked by loss of responsive musicality (Cooper and Murray, 1998; Field, 2010), and the principles of this fundamental patterning of human sound making by body movement are applied with benefit in therapy and 
teaching (Malloch and Trevarthen, 2009). Musical forms of communication support language learning at later stages of life as well (Ludke, 2009).

\subsection{Proto-language as a social/emotional advance, animated by development of left hemisphere skills for discretization and serial ordering of learned vocal sounds and gestures of narration.}

Infants begin to combine learned vocalizations and gestures after the first birthday to make utterances that imitate simplified adult speech. A normally developing child soon names persons, objects and actions, and responds to words, especially to their own name and the name of familiar persons and pets. By the end of the second year a rapid accumulation of a vocabulary begins and the child begins to use serial combinations of words. From this point one can study the development of true language (McNeill, 1970; Locke, 1993). Clearly it depends on the biological adaptations of the human body and brain for narrating the purposeful and emotionally valued experiences and achievements of life with other speaking human beings (Lenneberg, 1967; Bruner, 1983). It shows systematic distortion in developmental disorders such as autism, which offer additional evidence of an age related process governing the growth and differentiation of intersubjective awareness and shared agency (Trevarthen and Aitken, 2003; Trevarthen et al., 2006; Saint-Georges et al., 2010). The linguist Michael Halliday (Halliday, 1975) developed a socio-linguistic theory sensitive to the expressiveness of non-verbal vocalizations and gestures to chart the progress of his son to fluent use of words through the first two years. He identified these developmental phases:

Birth to 9 months, 'protoconversation', changing to 'conversation';

10 to 15 months, 'proto-language', changing to 'language';

15 to 20 months, 'proto-narrative and dialogue' changing to 'narrative and dialogue', and, after 20 months, 'proto-discourse'.

Similar transitions in representations leading to language, with varied interpretations, usually led by cognitive or linguistic theory, have been charted by Bates (1979) and Nelson (1996). Bruner (1990) and Rogoff (2003), who are interested in the interpersonal context of story-making and the learning of meaning, note that the purposes and procedures in narrating with young children may vary greatly across cultures. Gestures add metaphorical richness to conversational speech at all ages (Goldin-Meadow and McNeill, 1999) constituting a component of all languages, complementary to speech (McNeill, 2005). A deaf baby may substitute learning of contrived hand movements for spoken words, mastering hand sign language through comparable ages (Volterra, 1981; Petitto and Marentette, 1991). Donaldson (1992) gives an account of the growth of modes of narrative and explanation by expansion of the imagination and purposefulness or 'locus of concern' in late infancy and pre-school years, which development is reflected in the utterances of children before they develop what she calls the 'construct mode' of mind around three or four years. Hobson (2002) describes in similar terms how the foundations of thought are built in the affective communications of infancy, and Lüdtke (2011) reviews the evidence that relational emotions play a key role at all stages of semiotic and linguistic development and in language learning and language therapy.

The change from intuitive sharing of actions and feelings in intimate affectionate attachment to family and friends to mastery of the skills of a culture and its speaking is animated by growth of the brain with development of regulation of intentions and awareness in the left cerebral cortex. For several years the creative and cooperative imagination of the child, which was apparent at birth, remains the primary motivator for cultural learning, before formal teaching in the tools of culture and its social institutions can be accepted and effective (Halliday and Matthiessen, 2004; Bateman, 
Hois, Ross, and Tenbrink, 2010; Trevarthen, 2011b). At no point is development of mastery of language independent of the emotional regulation of human initiative and its sharing. Natural language is an artful tool for extending the innate motives for cooperative awareness and cultural learning, not just an abstract technical system of symbols for artificial representation and logical explanation (Reid, 1764).

\section{Conclusion}

To understand how language can share intentions, experiences and feelings, and how it must be represented widely in the brain, we recognize that the sense of words is transmitted to a child initially by rhythmically patterned movement of the whole body, and is taken up by perceptive response to other persons' self-related feelings for their experiences and prospects of action. Language is a function of intersubjective resonance of conscious embodied agency and aesthetic and moral emotions. All these requirements have manifestations in a newborn infant, and they can be traced back to species-specific organic and psychological capacities emerging in the human embryo and fetus. We are made for sympathetic cooperative creativity, and we learn words to define its purposes.

A new research field of research focusing on the actions of emotional, embodied communication and their development is challenging developmental psychologists, psychiatrists, cognitive neuroscientists, sociologists, anthropologists and philosophers, as well as language scientists, to combine their knowledge and methods to discover, in detail, how gesture and voice become discretized as syllables, words, and phrases, and how they are serially ordered to make meaningful propositional narrations. We will need to study more closely how movements are made and sensed in affective company for joint meaning-making, and to follow them through all the stages by which language is prepared for, mastered and elaborated. This work promises a new understanding of how language evolved, taking into account its rich embodied origins in the feeling and sharing of states of mind in rhythmic musicality of agency in the human brain and body.

\section{Further reading}

Bråten, Stein 2009 The Intersubjective Mirror in Infant Learning and Evolution of Speech. Amsterdam/Philadelphia: John Benjamins.

Bruner, Jerome S. 1990 Acts of Meaning. Cambridge, MA: Harvard University Press.

Malloch, Stephen and Colwyn Trevarthen (eds.) 2009 Communicative Musicality: Exploring the Basis of Human Companionship. Oxford: Oxford University Press.

Reddy, Vasudevi 2008 How Infants Know Minds. Cambridge, MA: Harvard University Press.

Stern, Daniel N. $\quad 2010$ Forms of Vitality: Exploring Dynamic Experience in Psychology, the Arts, Psychotherapy and Development. Oxford: Oxford University Press.

\section{References}

Aitken, Kenneth J. and Colwyn Trevarthen 1997 Self-Other Organization in Human Psychological Development. Development and Psychopathology, 9: 651-675. 
Als, Heidelise 1995 The Preterm Infant: A Model for the Study of Fetal Brain Expectation. In J.P. Lecanuet, W.P Fifer, N.A. Krasnegor and W.P. Smotherman (Eds.), Fetal Development: A Psychobiological Perspective. (pp. 439-471). Hillsdale, NJ: Erlbaum.

Bateman, John A. Joana Hois, Robert Ross, and Thora Tenbrink 2010 A Linguistic Ontology of Space for Natural Language Processing. Artificial Intelligence, 174(14): 1027-1071.

Bates, Elizabeth 1979 The Emergence of Symbols: Cognition and Communication in Infancy. New York: Academic Press.

Bateson, William 1894 Materials for the Study of Variation Treated with Especial Regard to Discontinuity in the Origin of Species. Baltimore and London: Johns Hopkins University Press.

Beddington, Rosa S. P. and Elizabeth J. Robertson 1999 Axis Development and Early Asymmetry in Mammals. Cell, 96: 195-209.

Bernard, Claude 1865 Introduction À La Médecine Expérimentale. Paris: Bordas.

Bernstein, Nikolai A. 1967 The Co-Ordination and Regulation of Movements. Oxford: Pergamon Press.

Bloom, Lois 2002 The Transition From Infancy to Language: Acquiring the Power of Expression. Cambridge: Cambridge University Press.

Bråten, Stein (ed.). 1998 Intersubjective Communication and Emotion in Early Ontogeny. Cambridge: Cambridge University Press.

Bråten, Stein 2009 The Intersubjective Mirror in Infant Learning and Evolution of Speech. Amsterdam/Philadelphia: John Benjamins.

Bråten, Stein and Colwyn Trevarthen2007 Prologue: From Infant Intersubjectivity and Participant Movements to Simulations and Conversations in Cultural Common Sense. In On Being Moved: From Mirror Neurons to Empathy. Amsterdam/Philadelphia: John Benjamins.

Brazelton, T. Berry 1979 Evidence of Communication During Neonatal Behavioural Assessment. In Before Speech: The Beginning of Human Communication (pp. 79-88). London: Cambridge University Press.

Bruner, Emiliano 2010 Morphological Differences in the Parietal Lobes Within the Human Genus: A Neurofunctional Perspective. Current Anthropology, 51: S77-S88.

Bruner, Jerome S. 1983 Child's Talk: Learning to Use Language. New York: Norton.

Bruner, Jerome S. 1990 Acts of Meaning. Cambridge, MA: Harvard University Press.

Bruner, Jerome S. 2003 Making Stories: Law, Literature, and Life. New York: Farrar, Strauss, and Giroux. 
Buzsáki, Gyoergy 2006 Rhythms of the Brain. Oxford: Oxford University Press.

Castiello, Umberto, Cristina Becchio, Stefania Zoia, , Cristian Nelini, , Luisa Sartori, , Laura Blason, , Giuseppina D'Ottavio, , Maria Bulgheroni and Vittorio Gallese 2010 Wired to be social: The ontogeny of human interaction. PLoS ONE, 5(10): e13199.

Condon, William S. and Louis W. Sander 1974 Neonate movement is synchronized with adult speech: Interactional participation and language acquisition. Science, 183: 99-101.

Cooper, Peter J. and Lynne Murray 1998 Fortnightly review: Postnatal depression. British Medical Journal, 316: 1884-1886.

Damásio, António 2010 Self Comes to Mind: Constructing the Conscious Brain. Pantheon Books.

Darwin, Charles 1872 The Expressions of Emotion in Man and Animals. London: Methuen.

De Vries, J. I. P. (Hanneke), Visser, G. H. A. and Heinz. F. R. Prechtl 1982 The emergence of fetal behavior, I. Qualitative aspects. Early Human Development, 7: 301-322.

Decasper, Anthony J and Phyllis Prescott 2009 Lateralized processes constrain auditory reinforcement in human newborns. Hearing Research, 255: 135-141.

Donald, Merlin 2001 A Mind So Rare: The Evolution of Human Consciousness. London and New York: Norton.

Donaldson, Margaret 1992 Human Minds: An Exploration. London: Allen Lane.

Edelman, Gerald M. 1988 Topobiology: An Introduction to Molecular Embryology. New York: Basic Books.

Ekman, Paul and Wallace V. Friesen 1969 The Repertoire of Nonverbal Behavior: Categories, Origins, Usage, and Coding. Semiotica, 22: 353-374.

Field, Tiffany 2010 Postpartum Depression Effects on Early Interactions, Parenting, and Safety Practices: A Review. Infant Behavior and Development, 33: 1-6.

Fónagy, Iván 2001 Languages Within Language: An Evolutive Approach. (13). Amsterdam/Philadelphia: John Benjamins.

Gallese, Vittorio 2001 The 'Shared Manifold' Hypothesis: From Mirror Neurons to Empathy. Journal of Conciousness Studies, 8(5-7): 33-50.

Gibson, James J. 1966 The Senses Considered as Perceptual Systems. Boston: Houghton Mifflin.

Goldin-Meadow, Susan and David Mcneill 1999 The role of gesture and mimetic representation in making language. In M. C. Corballis and E. G. Lea (Eds.), The Descent of Mind: 
Psychological Perspectives on Hominid Evolution (pp. 155-172). Oxford: Oxford University Press.

Gratier, Maya 2003 Expressive timing and interactional synchrony between mothers and infants: Cultural similarities, cultural differences, and the immigration experience. Cognitive Development, 18: 533-554.

Gratier, Maya and Colwyn Trevarthen 2008 Musical narratives and motives for culture in mother-infant vocal interaction. Journal of Consciousness Studies, 15: 122-158.

Halliday, Michael A. K. and Christian M. I. M. Matthiessen 2004 An Introduction to Functional Grammar, 3rd Edition. London: Arnold.

Halliday, Michael A. K. 1975 Learning How to Mean: Explorations in the Development of Language. London: Edward Arnold.

Halliday, Michael A. K. 1978 Language as Social Semiotic: The Social Interpretation of Language and Meaning. London: Edward Arnold.

Hamilton, William J., James D Boyd. and Harland W. Mossman 1962 Human Embryology: Prenatal Development of Form and Function. Cambridge: Heffer and Sons.

Hevner, Robert F. $\quad 2000 \quad$ Development of connections in the human visual system during fetal mid-gestation: A dil-tracing study. Journal of Neuropathology and Experimental Neurology, 59: 385-392.

Hobson, Peter 2002 The Cradle of Thought: Exploring the Origins of Thinking. Oxford: Macmillan.

Hubley, Penelope and Colwyn Trevarthen 1979 Sharing a task in infancy. In I. Uzgiris (Ed.), Social Interaction During Infancy (pp. 57-80). San Francisco: Jossey-Bass.

Jakobovits, Akos A. 2009 Grasping activity in utero: A significant indicator of fetal behavior. Journal of Perinatal Medicine, 37: 571-572.

James, David, Mary Pillai and John Smoleniec 1995 Neurobehavioral development of the human fetus. In J.-P. Lecanuet, W.P. Fifer, N.A. Krasnegor and W.P. Smotherman (Eds.), Fetal Development: A Psychobiological Perspective (pp. 101-128). Hillsdale, NJ: Erlbaum.

Jeannerod, Marc 1994 The representing brain: Neural correlates of motor intention and imagery. Behavioral and Brain Sciences, 17: 187-245.

Kendon, Adam $\quad 1980$ Gesticulation and speech: Two aspects of the process of utterance. In M.R. Key (Ed.), The Relationship of Verbal and Nonverbal Communication. The Hague: Mouton.

Larroche, Jeanne-Claudie 1981 The marginal layer in the neocortex of a 7 week-old human embryo: A light and electron microscopy study. Anatomy and Embryology, 162: 301-312. 
Lashley, Karl S. 1951 The problem of serial order in behavior. In L. A. Jeffress (Ed.), Cerebral Mechanisms in Behavior (pp. 112-136). New York: Wiley.

Lecanuet, Jean-Pierre, William P, Fifer, Norman A. Krasnegor, and William P. Smotherman (eds.) 1995 Fetal Development: A Psychobiological Perspective. Hillsdale, NJ: Erlbaum.

Lee, David N. 2005 Tau in action in development. In J. J. Rieser, J. J. Lockman and C. A. Nelson (Eds.), Action as an Organiser of Learning. Hillsdale, New Jersey: Erlbaum.

Lee, David N. 2009 General tau theory: Evolution to date. Perception, 38: 837-858.

Lenneberg, Eric H. 1967 Biological Foundations of Language. New York: John Wiley and Sons.

Locke, John L.1993 The Child's Path to Spoken Language. Cambridge, MA: Harvard University Press.

Ludke, Karen 2009 Teaching foreign languages through songs. In Practical Educational Workbook for Teachers to Use Songs in the Modern Language Classroom. (pp. 1-40). Edinburgh: University of Edinburgh.

Lüdtke, Ulrike 2011 Relational emotions in semiotic and linguistic development: Towards an intersubjective theory of language learning and language therapy. In J. Zlatev, T. Racine, U. Lüdtke and A. Foolen (Eds.), Moving Ourselves, Moving Others: Motion and Emotion in Consciousness, Intersubjectivity and Language. Amsterdam: John Benjamins.

MacNeilage, Peter F. 2008 The Origin of Speech. Oxford: Oxford University Press.

MacNeilage, Peter F. 2011 Lashley's serial order problem and the acquisition/evolution of speech. Cognitive Critique, 3, 49-83. University of Minnesota: Center for Cognitive Sciences.

Malloch, Stephen 1999 Mothers and infants and communicative musicality. Musicae Scientiae, Special Issue Rhythms, Musical Narrative, and the Origins of Human Communication: 29-57.

Malloch, Stephen and Colwyn Trevarthen (eds.) 2009 Communicative Musicality. Oxford: Oxford University Press.

McNeill, David 1970 The Acquisition of Language: The Study of Developmental Psycholinguistics. New York: Harper and Row.

McNeill, David 2005 Gesture and Thought. Chicago: University of Chicago Press.

Merker, Bjørn 2008 Ritual Foundations of human uniqueness. In S. Malloch and C. Trevarthen (eds.), Communicative Musicality: Exploring the Basis of Human Companionship (pp. 4560). Oxford: Oxford University Press.

Merker, Bjørn 2009a Returning language to culture by way of biology. Behavioral and Brain Sciences, 32(5): 460. 
Merker, Bjørn 2009b Ritual foundations of human uniqueness. In S. Malloch and C. Trevarthen (Eds.), Communicative Musicality: Exploring the Basis of Human Companionship. (pp. 4560). Oxford.: Oxford University Press.

Merker, Bjørn 2012 The vocal learning constellation: Imitation, ritual culture, encephalization. In Nicholas Bannan, ed. Music, Language, and Human Evolution. Oxford: Oxford University Press.

Merker, Bjørn 2005 The liabilities of mobility: A selection pressure for the transition to consciousness in animal evolution. Consciousness and Cognition, 14: 89-114.

Murray, Lynne and Colwyn Trevarthen 1985 Emotional regulation of interactions between two-month-olds and their mothers. In Social Perception in Infants (pp. 177-197). Norwood, NJ: Ablex.

Nagy, Emese 2011 The newborn infant: A missing stage in developmental psychology. Infant and Child Development, 20(1): 3-19.

Nagy, Emese 2008 Innate intersubjectivity: Newborns' sensitivity to communication disturbance. Developmental Psychology, 44(6): 1779-1784.

Nagy, Emese and Peter Molnar 2004 Homo imitans or Homo provocans? Human imprinting model of neonatal imitiation. Infant Behavior and Development, 27: 54-63.

Narváez, Darcia, Jaak Panksepp, Alan N.Schore and Tracy Gleason (eds.) 2011 Human Nature, Early Experience, and the Environment of Evolutionary Adaptedness. New York: Oxford University Press.

Nelson, Katherine 1996 Language in Cognitive Development: Emergence of the Mediated Mind. New York: Cambridge University Press.

Northoff, Georg and Panksepp, Jaak 2008 The trans-species concept of self and the subcorticalcortical midline system. Trends in Cognitive Sciences, 12: 259-264.

Okado, Nobuo $\quad 1980$ Development of the human cervical spinal cord with reference to synapse formation in the motor nucleus. The Journal of Comparative Neurology, 191: 495513.

Osborne, Nigel 2009 Towards a chronobiology of musical rhythm. In S. Malloch and C. Trevarthen (Eds.), Communicative Musicality: Exploring the Basis of Human Companionship. (pp. 545-564). Oxford: Oxford University Press.

Packard, Andrew 2006 Contribution to the whole (H). Can squids show us anything that we did not already know? Biology and Philosophy, 21: 189-211.

Pander, Christian Heinrich 1817 Beiträge zur Entwickelungseschichte des Hünchens im Eye. Würzburg: Brönner. 
Panksepp, Jaak 1998 Affective Neuroscience: The Foundations of Human and Animal Emotions. New York: Oxford University Press.

Panksepp, Jaak and Georg Northoff 2009 The trans-species core self: The emergence of active cultural and neuro-ecological agents through self-related processing within subcorticalcortical midline networks. Consciousness and Cognition, 18: 193-215.

Panksepp, Jaak and Colwyn Trevarthen 2009 The neuroscience of emotion in music. In S. Malloch and C. Trevarthen (Eds.), Communicative Musicality: Exploring the Basis of Human Companionship. (pp. 105-146). Oxford: Oxford University Press.

Papoušek, Mechthild 1994 Melodies in caregivers' speech: A species specific guidance towards language. Early Development and Parenting, 3: 5-17.

Penfield, Wilder and Herbert H. Jasper 1954 Epilepsy and the Functional Anatomy of the Human Brain. London: Little, Brown, and Co.

Petitto, Laura A. and Paula F. Marentette 1991 Babbling in the manual mode: Evidence for the ontogeny of language. Science, 251: 1493-1496.

Pfaff, Donald W. 2006 Brain Arousal and Information Theory: Neural and Genetic Mechanisms. Cambridge, MA: Harvard University Press.

Piontelli, Alessandra 2010 Development of Normal Fetal Movements: The First 25 Weeks of Gestation. Springer-Verlag.

Piontelli, Alessandra 1992 From Fetus to Child. London: Routledge.

Piontelli, Alessandra 2002 Twins: From Fetus to Child. London: Routledge.

Prechtl, Heinz F. R. 1986 Prenatal motor behaviour. In M. Wade and H. T. A. Whiting (Eds.), Motor Development in Children: Aspects of Coordination and Control. (pp. 53-64). Amsterdam: Elsevier, North-Holland.

Prigogine, Ilya and Isabelle Stengers 1984 Order Out of Chaos: Man's New Dialogue With Nature. Flamingo.

Reddy, Vasudevi 2008 How Infants Know Minds. Cambridge, MA: Harvard University Press.

Reid, Thomas 1764 An Inquiry Into the Human Mind on the Principles of Common Sense. Edinburgh: A. Kinkaid and J. Bell.

Reissland, Nadja, Brian Francis, James Mason and Karen Lincoln 2011 Do Facial expressions develop before birth? PLoS ONE, 6(8): 1-7.

Rogoff, Barbara 2003 The Cultural Nature of Human Development. Oxford: Oxford University Press. 
Rommetveit, Ragnar 1998 Intersubjective attunement and linguistically mediated meaning in discourse. In S. Bråten (Ed.), Intersubjective Communication and Emotion in Early Ontogeny. (pp. 354-371). Cambridge: Cambridge University Press.

Royal College of Obstetricians and Gynaecologists, 2010 Fetal Awareness: Review of Research and Recommendations for Practice. London: Royal College of Obstetricians and Gynaecologists.

Saint-Georges, Catherine, Ammar Mahdhaoui, Mohamed Chetaoani, , Raquel S. Cassel, MarieChristine Laznik, Fabio Apicella, , Pietro Muratori, Sandra Maestro, Filippo Muratori, and David Cohen 2010 Do parents recognize autistic deviant behavior long before diagnosis? Taking into account interaction using computational methods. PLoS ONE, 6(78): e22393.

Schore, Alan N. 2011 Bowlby's environment of evolutionary adaptedness: Recent studies on the interpersonal neurobiology of attachment and emotional development. In D. Narvaez, J. Panksepp, A. Schore and T. Gleason (Eds.), Human Nature, Early Experience, and the Environment of Evolutionary Adaptedness. New York: Oxford University Press.

Sebeok, Thomas A. 1977 How Animals Communicate. Bloomington: Indiana University Press.

Sebeok, Thomas A. 1994 Signs: An Introduction to Semiotics. Toronto: University of Toronto Press Inc.

Sherrington, Charles 1906 The Integrative Action of the Nervous System. New Haven, CT: Yale University Press.

Sinigaglia, Corrado and Giacomo Rizzolatti 2011 Through the looking glass: Self and others. Consciousness and Cognition, 20: 64-74.

Sperry, Roger W. 1952 Neurology and the mind-brain problem. American Scientist, 40: 291312.

Stern, Daniel N. 2000 The Interpersonal World of the Infant. (Second edition) New York: Basic Books.

Stern, Daniel N. $\quad 2010 \quad$ Forms of Vitality. Oxford: Oxford University Press.

Tallandini, Maria A. and Chiara Scalembra 2006 Kangaroo mother care and mother-premature infant dyadic interaction. Infant Mental Health Journal, 27(3): 251-275.

Trevarthen, Colwyn 1979 Communication and cooperation in early infancy: A description of primary intersubjectivity. In M. Bullowa (Ed.), Before Speech: The Beginning of Human Communication. (pp. 321-347). London: Cambridge University Press.

Trevarthen, Colwyn 1985 Neuroembryology and the development of perceptual mechanisms. In F. Falkner and J.M. Tanner (Eds.), Human Growth (2nd ed., pp. 301-383). New York: Plenum. 
Trevarthen, Colwyn 1986a Development of intersubjective motor control in infants. In M.G Wade and H.T.A. Whiting (Eds.), Motor Development in Children: Aspects of Coordination and Control. (pp. 209-261). Dordrecht: Martinus Nijhoff.

Trevarthen, Colwyn 1986b Form, significance, and psychological potential of hand gestures in infants. In J-L Nespoulous, P Perron and A R Lecours (Eds.), The Biological Foundation of Gestures: Motor and Semiotic Aspects (pp. 149-202). Hillsdale, NJ: Erlbaum.

Trevarthen, Colwyn 1990 Signs before speech. In T. A. Sebeok and J. Umiker-Sebeok (Eds.), The Semiotic Web 1989 (pp. 689-755). Berlin: Mouton de Gruyter.

Trevarthen, Colwyn 1996 Lateral asymmetries in infancy: Implications for the development of the hemispheres. Neuroscience and Biobehavioral Reviews, 20(4): 571-586.

Trevarthen, Colwyn 1999 Musicality and the Intrinsic Motive Pulse: Evidence from human psychobiology and infant communication. Musicae Scientiae, Special Issue Rhythms, Musical Narrative, and the Origins of Human Communication: 157-213.

Trevarthen, Colwyn 2004 Brain development. In R.L. Gregory (Ed.), Oxford Companion to the Mind (pp. 116-127). Oxford and New York: Oxford University Press.

Trevarthen, Colwyn 2005 Stepping away from the mirror: Pride and shame in adventures of companionship and refelections on the nature and emotional needs of infant intersubjectivity. In C. S. Carter, L. Ahnert, K. E. Grossman, S. B. Hrdy, M. E. Lamb, S. W. Porges and N. Sachser (Eds.), Attachment and Bonding: A New Synthesis. (pp. 55-84). Cambridge, MA: The MIT Press.

Trevarthen, Colwyn 2011a Born for art, and the joyful companionship of fiction. In D. Narvaez, J. Panksepp, A. Schore and T. Gleason (Eds.), Human Nature, Early Experience and the Environment of Evolutionary Adaptedness. New York: Oxford University Press.

Trevarthen, Colwyn 2011b What young children give to their learning, making education work to sustain a community and its culture. European Early Childhood Education Research Journal, 19(2): 173-193.

Trevarthen, Colwyn 1998 The concept and foundations of intersubjectivity. In S. Braten (Ed.), Intersubjective Communication and Emotion in Early Ontogeny (pp. 15-46). Cambridge: Cambridge University Press.

Trevarthen, Colwyn 2009 Human biochronology: On the source and functions of 'musicality'. In R. Hass and V. Brandes (Eds.), Music That Works. Wien and New York: Springer.

Trevarthen, Colwyn and Kenneth J. Aitken 2003 Regulation of brain development and agerelated changes in infants' motives: The developmental function of regressive periods. In M. Heimann (Ed.), Regression Periods in Infancy (pp. 107-184). Mahwah, NJ: Erlbaum.

Trevarthen, Colwyn, Kenneth J. Aitken, Emese Nagy, , Jonathan T. Delafield-Butt and Marie Vandekerckhove 2006 Collaborative regulations of vitality in early childhood: Stress in intimate relationships and postnatal psychopathology. In D. Cicchetti and D. J. Cohen (Eds.), Developmental Psychopathology (pp. 65-126). New York: John Wiley and Sons. 
Trevarthen, Colwyn and Jonathan T. Delafield-Butt 2011 Biology of shared meaning and language development: Regulating the life of narratives. In M. Legerstee, D. Haley and M. Bornstein (Eds.), The Developing Infant Mind: Integrating Biology And Experience. New York: Guildford Press (in prep.).

Trevarthen, Colwyn, Jonathan T. Delafield-Butt, and Benjamin Schögler 2011 Psychobiology of musical gesture: Innate rhythm, harmony and melody in movements of narration. In A. Gritten and E. King (Eds.), Music and Gesture Ii. Aldershot: Ashgate.

Trevarthen, Colwyn and Penelope Hubley 1978 Secondary intersubjectivity: Confidence, confiding and acts of meaning in the first year. In A. Lock (Ed.), Action, Gesture and Symbol (pp. 183-229). London: Academic Press.

Trevarthen, Colwyn and Katerina Logotheti 1987 First symbols and the nature of human knowledge. In J. Montangero, A. Tryphon and S. Dionnet (Eds.), Symbolisme Et Connaissance/Symbolism and Knowledge (pp. 65-92). Geneva: Jean Piaget Archives Foundation.

Tulving, Endel 2002 Episodic memory: From mind to brain. Annual Review of Psychology, 53: 1-25.

Turner, Robert and Andreas A. Ioannides 2009 Brain, music, and musicality: Inferences from neuroimaging. In S. Malloch and C. Trevarthen (Eds.), Communicative Musicality: Exploring the Basis of Human Companionship (pp. 147-184). Oxford: Oxford University Press.

Turner, Victor W. 1982 From Ritual to Theatre: The Human Seriousness of Play. New York: Performing Arts Journal Publications.

Turner, Victor W. and Edward M. Bruner(eds.). 1986 The Anthropology of Experience. Urbana: University of Illinois Press.

Tylén, Kristian, Ethan Weed, Mikkel Wallentin, , Andreas Roepstorff and Chris D. Frith 2010 Language as a tool for interacting minds. Mind and Language, 25: 3-29.

Vandekerckhove, Marie and Jaak Panksepp 2011 A neurocognitive theory of higher mental emergence: From anoetic affective experiences to noetic knowledge and autonoetic awareness. Neuroscience and Biobehavioral Reviews, 35(9): 2017-2025.

Volterra, Virginia 1981 Gestures, signs and words at two years: When does communication become language? Sign Language Studies, 33: 351-362.

Von Hofsten, Claes 1993 Prospective control -- a basic aspect of action development. Human Development, 36: 253-270.

Von Hofsten, Claes 2004 An action perspective on motor development. Trends in Cognitive Sciences, 8: 266-272. 
Von Holst, Erich and Ursula Von St. Paul 1960 Vom Wirkungsgefüge der Triebe. Die Naturwissenschaften, 47: 409-422.

Von Uexküll, Jakob 1926 Theoretical Biology. London: Kegan Paul, Trench, Trubner, and Co.

Von Uexküll, Jakob 1957 A stroll through the worlds of animals and men. In C. H. Schiller (Ed.), Instinctive Behavior: The Development of a Modern Concept. (pp. 5-80). New York: International Universities Press.

Vygotsky, Lev 1978 Mind in Society. Cambridge, MA: Harvard University Press.

Waddington, Conrad Hal 1940 Organisers and Genes. Cambridge: Cambridge University Press.

Watt, Douglas F. 2004 Review of Beauregard, M. (Ed.) 2004. "Consciousness, Emotional Self-Regulation, and The Brain". Journal of Consciousness Studies, 11 (9)(9): 77-82.

Whitehead, Alfred North 1929 Process and Reality. New York: Macmillan.

Windle, William F. 1970 Development of neural elements in human embryos of four to seven weeks of gestation. Experimental Neurology, 5(Supplement): 44-83.

Wittmann, Marc 2009 The inner experience of time. Philosophical Transactions of the Royal Society B -Biological Sciences, 364: 1955-1967.

Wolff, Peter H. 1966 The causes, controls, and organization of behavior in the neonate. Psychological Issues, 5(Monograph 17): 1-19.

Zoia, Stefania, Laura Blason, Giuseppina D'Ottavio, , Maria Bulgheroni, Eva Pezzetta, Aldo Scabar, and Umberto Castiello, 2007 Evidence of early development of action planning in the human foetus: A kinematic study. Experimental Brain Research, 176: 217226. 